\title{
Polymorphisms of the PRNP gene in Chinese populations and the identification of a novel insertion mutation
}

\author{
Shui-Liang $\mathrm{Yu}^{1,4}$, Lei Jin ${ }^{2}$, Man-Sun Sy ${ }^{1,3}$, Fang-Hua Mei ${ }^{1}$, Shu-Li Kang ${ }^{1}$, Gui-Hong Sun ${ }^{1}$, \\ Po Tien ${ }^{1}$, Fu-Sheng Wang*,2, and Geng-Fu Xiao*,1 \\ ${ }^{1}$ CJD Surveillance Unit, Modern Virology Research Center, College of Life Sciences, Wuhan University, Wuhan, Hubei \\ 430072, People's Republic of China; ${ }^{2}$ Beijing Institute of Infectious Disease, Beijing 302 Hospital of PLA, Beijing \\ 100039, People's Republic of China; ${ }^{3}$ Institute of Pathology, and Department of Neurosciences, School of Medicine, \\ Case Western Reserve University, Cleveland, OH 44120-1712, USA
}

The two common polymorphisms (385A $>$ G: $M 129 \mathrm{~V}$ and $655 \mathrm{G}>\mathrm{A}: \mathrm{E} 219 \mathrm{~K})$ in the human prion gene (PRNP) play important roles in the pathogenesis of Creutzfeldt-Jakob diseases. We screened a total of 626 individuals, who represent three ethnic populations of China, Han, Hui, and Uyghur, for the two polymorphisms. The frequencies of $\mathrm{M} / \mathrm{M}$ homozygote at residue 129 in these three groups differ significantly. The Han has a much higher frequency $(98 \%)$ than Hui $(85 \%)$ and Uyghur $(60 \%)$. On the other hand, the frequencies of the $\mathrm{E} / \mathrm{E}$ at residue 219 are higher in Uyghur (98\%) and Hui (96\%) than in Han (90\%). We also investigated two other less common variants of PRNP, a silent substitution at residue 117 (351A > G: A117A), and one octapeptide-repeat deletion (1-OPRD) in the octapeptide-coding region. We found three Uyghur individuals with silent substitution at residue 117 . Four Hui $(2.0 \%)$ and one Han $(0.5 \%)$ donors were found to be heterozygous for 1-OPRD. A novel three extra-repeat $(72 \mathrm{bp})$ insertion within the octapeptide-coding region was identified in one healthy 11 -years-old Hui. Identical mutation was also found in her mother but not her father.

European Journal of Human Genetics (2004) 12, 867-870. doi:10.1038/sj.ejhg.5201245

Published online 21 July 2004

Keywords: Creutzfeldt-Jakob diseases (CJD); prion; PRNP; polymorphism; Chinese populations; insertion mutation

\section{Introduction}

Human prion diseases have been classified as infectious, inherited, and sporadic form. Infectious human prion disease was most vividly demonstrated first in Kuru, and recently in variant Creutzfeldt-Jakob disease (vCJD). Approximately $10-15 \%$ of the human prion disease is

*Correspondence: Dr Geng-fu Xiao. Tel: + 8627 87166272; Fax: + 8627 87869897; E-mail: gxiao@whu.edu.cn and Dr Fu-Sheng Wang. Fax: +86 10 63831870; E-mail: fswang@public.bta.net.cn

${ }^{4}$ Current address: Department of Microbiology \& Immunology, Hubei College of Chinese Traditional Medicine, Wuhan, Hubei 430061, People's Republic of China

Received 26 February 2004; revised 28 April 2004; accepted 12 May 2004 inherited. More than 20 pathogenic mutations have been found in the coding sequence of the PRNP (MIM\# 176640) in patients. ${ }^{1}$ Most of the genetic alterations are point mutations, with the exception of genetic insertions occurring in the octapeptide repeat region. However, the majority of the cases of human prion diseases (85\%) occur sporadically by an unknown mechanism.

Certain polymorphisms in the PRNP could influence the incidence of prion disease. One of the most common polymorphisms concerns codon 129 , which may be either methionine (Met) or valine (Val) $(385 \mathrm{~A}>\mathrm{G}$ : M129 V). In Caucasians, Met homozygosity is a high risk factor for CJD, while heterozygosity is thought to be protective. ${ }^{1-5}$ 
Table 1 Genotype and allele frequencies of M129V and E219K in Chinese general populations

\begin{tabular}{|c|c|c|c|c|c|}
\hline & Hans of S.C. $(n=76)$ & Hans of N.C. $(n=129)$ & Hans $(n=205)$ & Huis $(n=198)$ & Uyghurs $(n=223)$ \\
\hline \multicolumn{6}{|l|}{ M129V } \\
\hline \multicolumn{6}{|c|}{ Genotype } \\
\hline $\mathrm{M} / \mathrm{M}$ & 73 (96\%) & 127 (98\%) & $200(97.6 \%)$ & 168 (84.8\%) & $134(60.1 \%)$ \\
\hline $\mathrm{M} / \mathrm{V}$ & $3(4 \%)$ & $2(2 \%)$ & $5(2.4 \%)$ & $29(14.6 \%)$ & $77(34.5 \%)$ \\
\hline $\mathrm{V} / \mathrm{V}$ & $0(0 \%)$ & $0(0 \%)$ & $0(0 \%)$ & $1(0.5 \%)$ & $12(5.4 \%)$ \\
\hline \multicolumn{6}{|c|}{ Allele frequency } \\
\hline$M$ & 0.980 & 0.992 & 0.988 & 0.922 & 0.774 \\
\hline V & 0.020 & 0.008 & 0.012 & 0.078 & 0.226 \\
\hline \multicolumn{6}{|l|}{ E219K } \\
\hline \multicolumn{6}{|c|}{ Genotype } \\
\hline $\mathrm{E} / \mathrm{E}$ & $64(84.2 \%)$ & $120(93 \%)$ & $184(89.8 \%)$ & $189(95.5 \%)$ & $218(97.8 \%)$ \\
\hline $\mathrm{E} / \mathrm{K}$ & $12(15.8 \%)$ & $9(7 \%)$ & $21(10.2 \%)$ & $9(4.5 \%)$ & $5(2.2 \%)$ \\
\hline $\mathrm{K} / \mathrm{K}$ & $0(0 \%)$ & $0(0 \%)$ & $0(0 \%)$ & $0(0 \%)$ & $0(0 \%)$ \\
\hline \multicolumn{6}{|c|}{ Allele frequency } \\
\hline $\mathrm{E}$ & 0.921 & 0.965 & 0.949 & 0.977 & 0.989 \\
\hline $\mathrm{K}$ & 0.079 & 0.035 & 0.051 & 0.023 & 0.011 \\
\hline
\end{tabular}

Approximately, $71 \%$ of sporadic CJD cases are $\mathrm{M} / \mathrm{M}$ homozygotes. ${ }^{5}$ Interestingly, all individuals with vCJD are homozygous with Met at codon $129 .{ }^{6}$ A recent study found that $\mathrm{M} / \mathrm{V}$ heterozygotes were over-represented among survivors of Kuru. It was postulated that prehistoric Kurulike epidemics, associated with the practice of cannibalism, might have caused the balancing selection of the M129V polymorphism. $^{7}$

Another PRNP gene polymorphism is at codon 219 (glutamate/lysine, $655 \mathrm{G}>\mathrm{A}$ : E219 K). This variant was found to be a common polymorphism (6\%) in Japanese, ${ }^{8}$ and in other populations in East Asia, South Asian Subcontinent, and Pacific, ${ }^{7,9}$ but has not been found in Europeans. ${ }^{10}$ Allele of $219 \mathrm{~K}$ is regarded as another protecting factor against sporadic CJD. ${ }^{8}$

Most of the information on the genotype and allele frequencies of human PRNP came from studies in Caucasians and Japanese. China is a multiracial country with a vast territory. We report the screening of 626 individuals representing three ethnic populations of China for four of the most common polymorphisms in PRNP.

\section{Materials and methods}

Genomic DNA was extracted by standard techniques from the blood of 626 unrelated healthy individuals representing three ethnic Chinese: Han $(n=205)$, Hui $(n=198)$, Uyghur $(n=223)$. The Han donors were from two municipal cities (Beijing and Shanghai) and 21 provinces covering most of China. We divided them into two groups by a geographical boundary (Qinling Mountain and Huaihe River): Han of south China $(n=76)$ and Han of north China $(n=129)$. The Hui donors were from Ge'ermu City in Qinghai province, and the Uyghur donors were from Kashi City in Xinjiang province.
To detect M129V, A117A polymorphism, the sense primer 5'-CAGAGCAGTCATTATGGCGAACCT-3' and antisense primer 5'-AGACCTTCCTCATCCCACTATCAG-3' were used to amplify the PRNP coding sequence in standard PCR conditions, then submitted to the endonuclease restriction enzymes NspI, PvuII, respectively. The digestion products were analyzed on $2 \%$ agarose gel. 1-Octapeptide repeat deletion (1-OPRD) and insertions were detected by examining agarose gel for size variations. Genotyping of codon 219 of PRNP gene was performed as described previously. ${ }^{11}$ Results of some individuals were confirmed by DNA sequencing. A $\chi^{2}$ test was used to determine the deviation from Hardy-Weinberg equilibrium and to compare genotype and allele frequencies in various populations.

\section{Results and discussion}

A total of 626 individuals were screened for the genotype and allele frequencies at codons 129 and 219 of PRNP (Table 1). Hardy-Weinberg equilibrium holds for all populations. We found that the genotype and allele frequencies of M129 V and E219 K distributed similarly in Han of south China and north China, or in Han of Mainland China and Taiwan, ${ }^{12}$ but differed significantly between the three Chinese ethnic groups. The Han has a much higher frequency (98\%) of $129 \mathrm{M} / \mathrm{M}$ homozygote than Hui $(85 \%)(P=0.000)$ and Uyghur $(60 \%)(P=0.000)$. On the other hand, the frequencies of the $\mathrm{E} / \mathrm{E}$ at residue 219 are higher in Uyghur (98\%) $(P=0.001)$ and Hui $(96 \%)$ $(P=0.047)$ than in Han $(90 \%)$. The frequencies of $\mathrm{M} 129 \mathrm{~V}$ and $\mathrm{E} 219 \mathrm{~K}$ are distributed in gradients with Hui in between those of Han and Uyghur.

Based on a report by Doh-ura et al, ${ }^{13}$ the $129 \mathrm{~V}$ allele frequency in Han Chinese (0.012) is different from that of 
Table 2 Comparison of estimated haplotype frequencies of PRNP in Chinese populations

\begin{tabular}{lccc}
\hline Haplotypes & Han & Hui & Uyghur \\
\hline A. 129M-219E-117A(gca)-1 OPRD(-) & $383(93.4 \%)$ & $352(88.9 \%)$ & $340(76.2 \%)$ \\
B. 129M-219E-117A(gca)-1 OPRD(+) & $1(0.2 \%)$ & $4(1.0 \%)$ & $0(0.0 \%)$ \\
C. 129M-219K-117A(gca)-1 OPRD(-) & $21(5.1 \%)$ & $9(2.3 \%)$ & $5(1.1 \%)$ \\
D. 129V-219E-117A(gca)-1 OPRD(-) & $5(1.2 \%)$ & $31(7.8 \%)$ & $98(22.0 \%)$ \\
E. 129V-219E-117A(gcg)-1 OPRD(-) & $0(0.0 \%)$ & $0(0.0 \%)$ & $3(0.7 \%)$ \\
Total & $410(100 \%)$ & $396(100 \%)$ & $446(100 \%)$ \\
\hline
\end{tabular}

Japanese (0.042) $(P=0.019)$. However, Mead et $\mathrm{al}^{7}$ recently reported that the frequency of the $129 \mathrm{~V}$ allele in Japanese is 0.01 . This discrepancy might be caused by small sample size in the Mead's study.

The $129 \mathrm{~V}$ allele frequency is much lower in Uyghur population (0.23) than in Caucasians ${ }^{5}(0.36)(P=0.000)$. However, the allele frequency of $129 \mathrm{~V}$ in Uyghur population was very close to that in Turkish ${ }^{14}(0.26)(P=0.408)$. The allele frequencies of $219 \mathrm{~K}$ in Han Chinese (0.05), Japanese $^{8}(0.06)$, and Indians ${ }^{7}(0.05)$ are very similar $(P=0.892)$. We did not detect any $\mathrm{K} / \mathrm{K}$ homozygotes at codon 219 . All $219 \mathrm{~K}$ alleles were linked with $129 \mathrm{M}$ allele in this study (Table 2) and all samples carrying $219 \mathrm{~K}$ allele were $129 \mathrm{M} / \mathrm{M}$ genotype except two individuals (one Hui and one Uyghur) who were $129 \mathrm{M} / \mathrm{V}$.

The A117A silent polymorphism was found in $11 \%$ of British $^{15}$ population, $5.4 \%$ of Germans, ${ }^{1}$ and $5 \%$ of Turkish $^{14}$ population. We found that only three Uyghur subjects $(1.3 \%)$ carried this polymorphism as heterozygotes. This mutation was not found in any Han or Hui in our study, or in other East Asians, such as Japanese, Thai. ${ }^{7}$ Sequencing analysis indicated that all the GCA-GCG substitutions at codon 117 were associated with $129 \mathrm{~V}$ allele (Table 2). These results are identical to previous reports. ${ }^{14-16}$ According to Mead et al, -31A - 117Ala (GCG) $-129 \mathrm{Val}+881 \mathrm{~A}$ allele represents the same rare haplotype, which might have originated from an ancestor in Europe. ${ }^{16}$ Thus, the three alleles with 117Ala (GCG) found in Uyghur could have originated from Europe. Data from the frequencies of $\mathrm{M} 129 \mathrm{~V}$ and $\mathrm{E} 219 \mathrm{~K}$ are also consistent with the thought that the Uyghur population is originated from an admixture of Europeans and East Asians. ${ }^{17}$

In normal individuals, there are five octapeptide-repeating elements within the N-terminal region of PRNP. One octapeptide-repeat ( $24 \mathrm{bp}$ ) deletion (1-OPRD), which is a nonpathogenic polymorphism, was found in four Hui $(1.0 \%)$ and one Han $(0.24 \%)$. 1-OPRD allele frequencies of other populations are $0.5 \%$ in Western Europeans, ${ }^{18} 0.54 \%$ in Italians, ${ }^{4} 0.45 \%$ in Germans ${ }^{1}$ and $1.0 \%$ in Turkish. ${ }^{14}$ The deletions in the five individuals in our study are all located upstream of codon 76 and were associated with $129 \mathrm{M}$ (Table 2).

The octapeptide-repeating region is important in the binding of divalent cations, such as copper and zinc. ${ }^{19,20}$

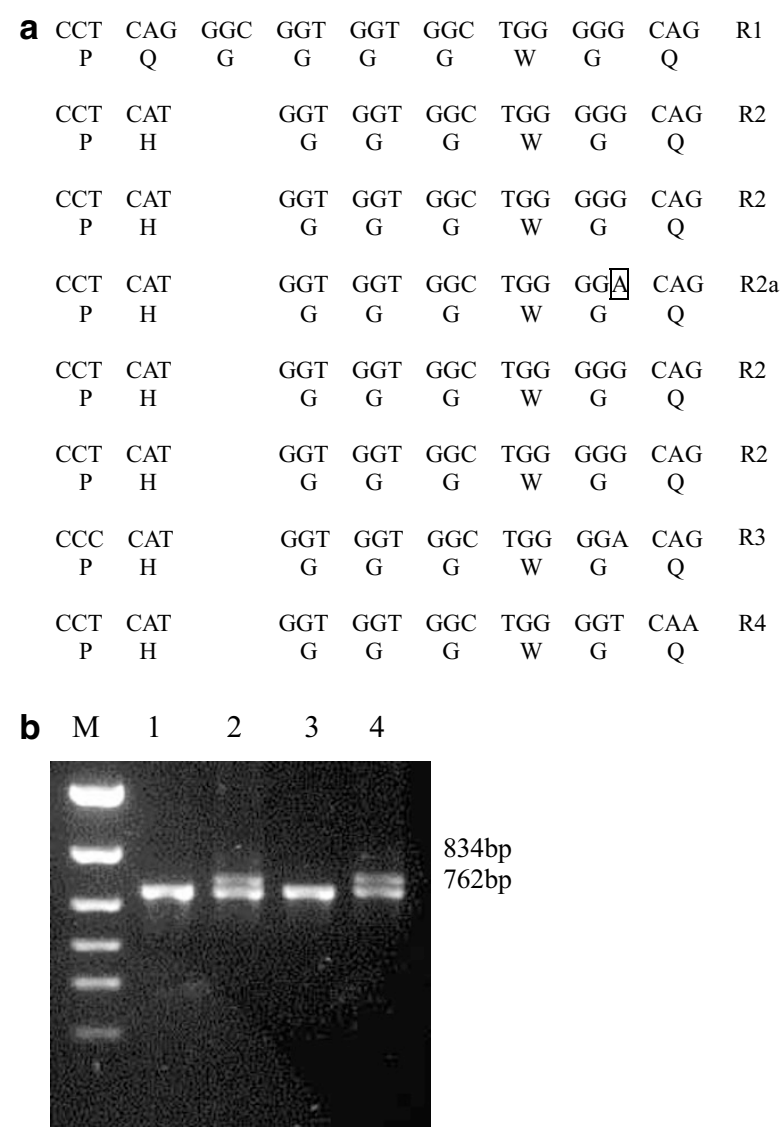

Figure 1 (a) Nucleotide sequence of codon 51-91 in the individual with an extra $72 \mathrm{bp}$ insertion. (b) Agarose gel (1.5\%) electrophoresis of PCR-amplified PRNP coding region (full length). $M$, markers (from top to bottom) of 1543, 994, 697, 515, 377, $237 \mathrm{bp}$; lane 1, father; lane 2, mother; lane 3, son; lane 4, daughter. The father and the son show only the normal $762 \mathrm{bp}$ fragment; the mother and the daughter heterozygous for allele with three extra repeats show an additional fragment of $834 \mathrm{bp}$.

Insertions of multiples of octamer repeats in this region have been associated with inherited prion diseases. ${ }^{1,21}$ The numbers of insertion range from one to nine octapeptide repeats, except three octapeptide repeats. In this study, we found a healthy girl in Hui ethnic group with a three extrarepeat $(72 \mathrm{bp})$ insertion within the octapeptide-coding region. Sequencing results show that the most likely 
sequence of repeats in this case is $\mathrm{R} 1, \mathrm{R} 2, \mathrm{R} 2, \mathbf{R 2} \mathbf{a}, \mathbf{R 2}, \mathbf{R 2}$, R3, R4, with the extra repeats of R2a, R2, R2 inserted between normal R2 and R3 repeats (Figure 1; GenBank AY458651). This mutation was linked with $129 \mathrm{M}$ allele. The genetic mechanism for the generation of the three extra repeats is probably unequal crossover, as described previously for other mutations with different numbers of insertion. $^{21}$ Identical mutation was also found in her mother but not in her father or a half-brother with a different mother. The girl's maternal grand parents died when they were in the six decades of life, and no medical record is available.

All insertion mutations have been found to be pathogenic, with the exception of one single case of an individual with four extra repeats, this 63 -years-old patient died of liver cirrhosis without history of neurological illness. $^{21}$ The earliest disease onset for an insertion mutation was reported in a US family with seven extra repeats. The age at onset was between 23 and 35 years, and the duration of disease ranged from 10 to 15 years. $^{21}$

At the present time, both the young girl and her mother, who is in her late 30s, are healthy. The mother comes from a large family with eight siblings and more than 300 relatives. Attempts have been made to collect as many blood samples and medical records as possible from this family. Hopefully, we shall be able to establish a more extensive genealogy and follow the clinical development of each individual with this novel mutation.

\section{Acknowledgements}

We would like to thank Dr. G. Barnard of Cambridge University, UK, for discussion and suggestions.

\section{References}

1 Windl O, Giese A, Schulz-Schaeffer W et al: Molecular genetics of human prion diseases in Germany. Hum Genet 1999; 105: 244-252.

2 Palmer MS, Dryden AJ, Hughes JT, Collinge J: Homozygous prion protein genotype predisposes to sporadic Creutzfeldt-Jakob disease. Nature 1991; 352: 340-342.

3 Collinge J, Palmer MS, Dryden AJ: Genetic predisposition to iatrogenic Creutzfeldt-Jakob disease. Lancet 1991; 337: $1441-1442$.

4 Salvatore M, Genuardi M, Petraroli R, Masullo C, DAlessandro M, Pocchiari M: Polymorphisms of the prion protein gene in Italian patients with Creutzfeldt-Jakob disease. Hum Genet 1994; 94 $375-379$.

5 Alperovitch A, Zerr I, Pocchiari M et al: Codon 129 prion protein genotype and sporadic Creutzfeldt-Jakob disease. Lancet 1999; 353: $1673-1674$

6 Brown P, Will RG, Bradley R, Asher DM, Detwiler L: Bovine spongiform encephalopathy and variant Creutzfeldt-Jakob disease: background, evolution, and current concerns. Emerg Infect Dis 2001; 7: 6-16.

7 Mead S, Stumpf MPH, Whiteld J et al: Balancing selection at the prion protein gene consistent with prehistoric Kurulike epidemics. Science 2003; 300: 640-643.

8 Shibuya S, Higuchi J, Shin R-W, Tateishi J, Kitamoto T: Protective prion protein polymorphisms against sporadic Creutzfeldt-Jakob disease. Lancet 1998; 351: 419.

9 Soldevila M, Calafell F, Andres AM et al: Prion susceptibility and protective alleles exhibit marked geographic differences. Hum Mutat 2003; 22: 104-105.

10 Petraroli R, Pocchiari M: Codon 219 polymorphism of PRNP in healthy caucasians and Creutzfeldt-Jakob disease patients. Am J Hum Genet 1996; 58: 888-889.

11 Furukawa H, Kitamoto T, Tanaka Y, Tateishi J: New variant prion prion in a Japanese family with Gerstmann-Strauessler syndrome. Mol Brain Res 1995; 30: 385-388.

12 Tsai M-T, Su Y-C, Chen Y-H, Chen C-H: Lack of evidence to support the association of the human prion gene with schizophrenia. Molecular Psychiatry 2001; 6: 74-78.

13 Doh-Ura K, Kitamoto T, Sakaki Y, Tateishi J: CJD discrepancy. Nature 1991; 353: 801-802.

14 Erginel-Unaltuna N, Peoc'h K, Komurcu E, Acuner TT, Issever $\mathrm{H}$, Laplanche JL: Distribution of the M129V polymorphism of the prion protein gene in a Turkish population suggests a high risk for Creutzfeldt-Jakob disease. Eur J Hum Genet 2001; 9: 965-968.

15 Palmer MS, van Leeven RH, Mahal SP, Campbell TA, Humphreys $\mathrm{CB}$, Collinge J: Sequence variation in intron of prion protein gene, crucial for complete diagnostic strategies. Hum Mutat 1996; 7: $280-281$.

16 Mead S, Mahal SP, Beck J et al: Sporadic - but not variant - Creutzfeldt-Jakob disease is associated with polymorphisms upstream of PRNP exon 1. Am J Hum Genet 2001; 69: 1225-1235.

17 Xiao FX, Yang JF, Cassiman JJ, Decorte R: Diversity at eight polymorphic Alu insertion loci in Chinese populations shows evidence for European admixture in an ethnic minority population from northwest China. Hum Biol 2002; 74: $555-568$.

18 Palmer MS, Mahal SP, Campbell TA et al: Deletions in the prion protein gene are not associated with CJD. Hum Mol Genet 1993; 2: $541-544$.

19 Brown DR, Qin K, Herms JW et al: The cellular prion protein binds copper in vivo. Nature 1997; 390: 684-687.

20 Watt NT, Hooper NM: The prion protein and neuronal zinc homeostasis. Trends Biochem Sci 2003; 28: 406-410.

21 Goldfarb LG, Brown P, McCombie WR et al: Transmissible familial Creutzfeldt-Jakob disease associated with five, seven, and eight extra octapeptide coding repeats in the PRNP gene. Proc Natl Acad Sci USA 1991; 88: 10926-10930. 